\begin{tabular}{l|l|l|l|l} 
Revue suisse Zool. & Tome 83 & Fasc. 1 & p. 255-262 & Genève, mars 1976
\end{tabular}

\title{
Towards the knowledge of tropical Protura
}

\author{
by \\ Josef NOSEK
}

With 4 figures

\section{SUMMARY}

Three new species Eosentomon ceylonicum sp. n., Eosentomon temannegarai sp. n. and Australentulus hauseri sp. n. are described. The description of a female of Eosentomon bolivari Bonet, 1949 is given.

\section{Eosentomon cyelonicum sp. $\mathrm{n}$.}

Figs. 1 A-I

Holotype: $\hat{\jmath}$ from Kandy, Udawattekele Sanctuary (Central Ceylon), $600 \mathrm{~m}$ alt. The sample was taken on the margin of forest 22.1.1970 C. Besuchet et I. Löbl leg.

Holotype mounted in Swan's medium kept in Muséum d'Histoire naturelle de Genève.

Description: Length of body $1200 \mu$, foretarsus without claw $120 \mu$.

Head. - Mouthparts with very strong striated mandible (fig. 1 C). Pseudoculus very distinct, $\mathrm{PR}=13$ (fig. $1 \mathrm{D}$ ). Clypeal apodeme strongly developed.

Thorax. - Spiracles are smaller than pseudoculus (fig. 1 E). Foretarsus is characterized with very long $a^{\prime}$ and $f_{1}$ sensillae. Sensillae $b_{1}^{\prime}$ and $b_{2}^{\prime}$ are broadened in their first half. Praetarsal sensilla $s$ overreaching the claw (figs. $1 \mathrm{~A}, \mathrm{~B}$ ). The ratio of sensillae on foretarsus on exterior side $a: b: x: c: d: e: f_{1}: f_{2}: g$ as $15.5: 22: 43: 17: 24: 22: 26: 15: 22.5$; on inner side $a^{\prime}: b_{1}^{\prime}: b_{2}^{\prime}: c^{\prime}$ as $52: 17.5: 17.5: 14$. TR $=6.7, \mathrm{BS}=1.7, \mathrm{EU}=0.8$. The hind tarsus with strong claw and very strong dorsal spine (fig. $1 \mathrm{~F}$ ).

Abdomen. - Central lobe of praecosta deeply incised (fig. $1 \mathrm{G}$ ). pi greatly bypassing $p_{1}$ in terg. I-VI (fig. $1 \mathrm{H}$ ). Squama genitalis $\hat{o}$ is characterized by very strong basal apodeme (fig. 1 I). Survey of chaetotaxy in Tuxen's system:

$\begin{array}{lccccccccc} & \text { I } & \text { II-III } & \text { IV } & \text { V-VI } & \text { VII } & \text { VIII } & \text { IX-X } & \text { XI } & \text { XII } \\ \text { terg. } & \frac{4}{10} & \frac{10}{16} & \frac{8}{16} & \frac{8}{16} & \frac{2^{x}}{16} & \frac{6}{9} & 8 & 8 & 9 \\ \text { stern. } & \frac{4}{4} & \frac{6}{4} & \frac{6}{10} & \frac{6}{10} & \frac{6}{10} & \frac{2}{7} & 4 & 8 & 12\end{array}$



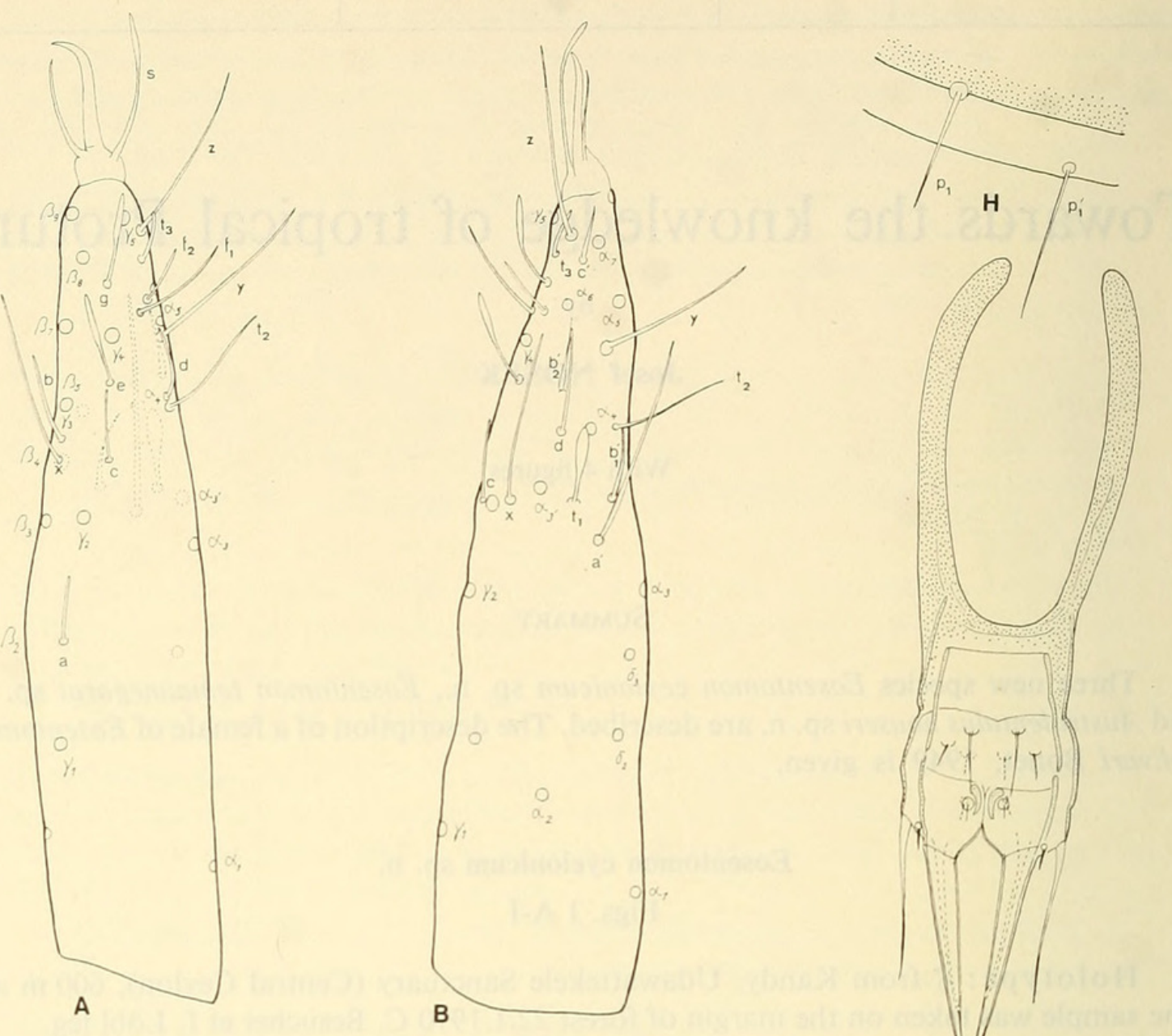

A

B

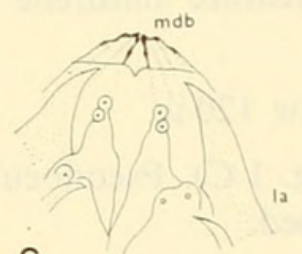

C

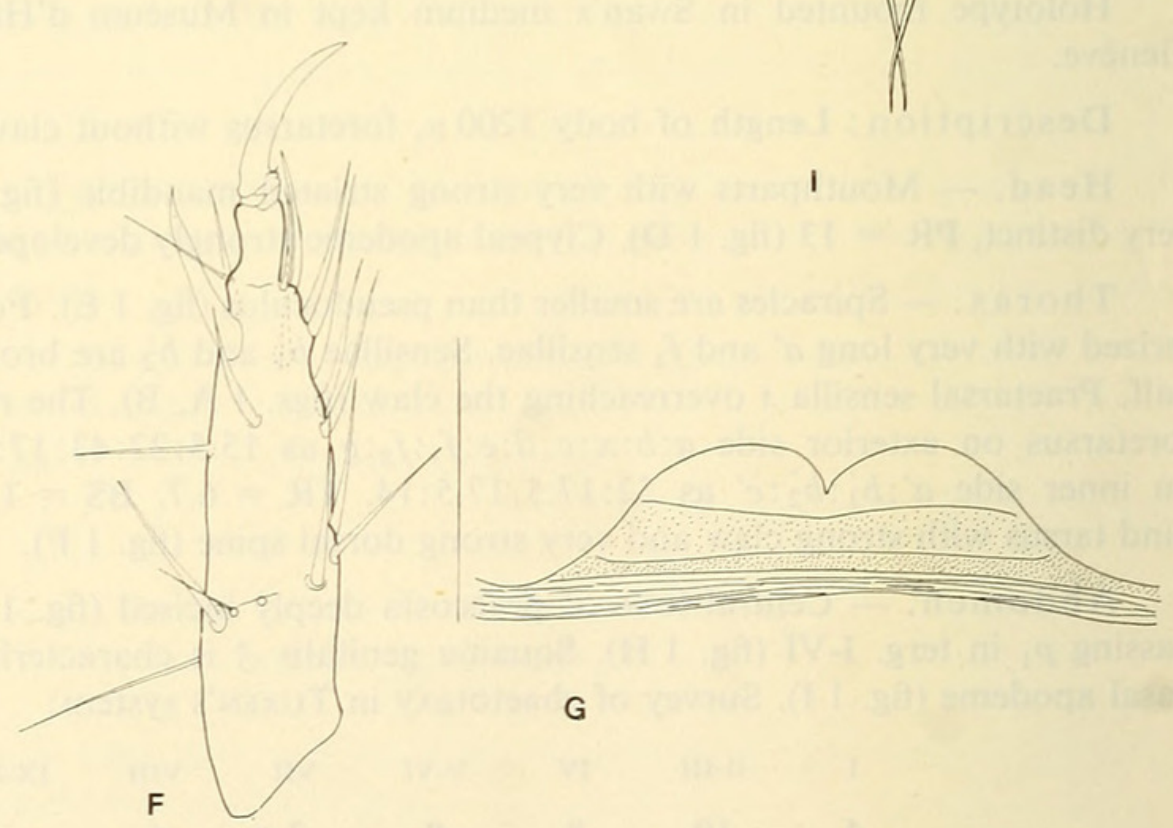

FIG. 1.

Eosentomon ceylonicum sp. n. $\hat{\jmath}$ : A. Foretarsus in ventral view. - B. Foretarsus in dorsal view. C. Mouthparts: mdb-mandible, la-lobus externus. - D. Pseudoculus. - E. Metathoracic spiracle. - F. The hind tarsus. - G. Central lobe of praecosta VI. - H. The ratio $p_{1}: p_{1}^{\prime}$ on terg. IV. - I. Male squama genitalis. 
Affinity. The chaetotaxy of Eosentomon ceylonicum sp. n. is closely related to Eosentomon womersleyi Bonet, 1942 known from Australia. It belongs probably to "swani" group.

\section{Eosentomon temannegarai sp. $\mathrm{n}$.}

Figs. 2 A-G

Holotype: $\hat{\jmath}$ from Teman Negara National Park (Malaysia) $240 \mathrm{~m}$ alt., climax lowland rainforest, 27.6.1973 P. Schauenberg leg.

Holotype mounted in Swan's medium kept in Muséum d'Histoire naturelle de Genève.

Description: Length of body $750 \mu$, foretarsus without claw $71 \mu$. Body colour: Thorax reddish brown, the rest of body dark yellow coloured.

Head. - The mouthparts are clearly seen but only in lateral position. Pseudoculi slightly divided with a rounded deepness in the first third (fig. $2 \mathrm{D}$ ); PR $=12$.

Thorax. - Spiracles approximately of the same length as pseudoculus (fig. 2 E). Foretarsus is characterized with the presence of $b_{1}^{\prime}$ and $b_{2}^{\prime}$, and with empodium a little longer than the claw. Sensillae $b, e, g$ nearly the same length. Praetarsal sensilla $s$ does not reach the tip of the claw (figs. $2 \mathrm{~A}, \mathrm{~B}, \mathrm{C}$ ). The ratio of sensillae on the exterior side of foretarsus $a: b: x: c: d: e: f_{1}: f_{2}: g$ as $12: 21: 29.5: 11: 13: 22: 12: 8: 20$; on inner side $a^{\prime}: b_{1}^{\prime}: b:{ }_{2}^{\prime} c^{\prime}$ as $18: 12: 19: 13$. TR $=4.0, \mathrm{BS}=1.1, \mathrm{EU}=1.1$. The hind tarsus with very strong unguis and weakly developed dorsal spine (fig. $2 \mathrm{~F}$ ).

Abdomen. - Central lobe of praecosta deeply incised. $p_{1}$ by-passing $p_{1}^{\prime}$ in terg. I-VI (fig. 2 G).

Survey of chaetotaxy in TUXEN's system:

$\begin{array}{lcccccccr} & \text { I } & \text { II-III } & \text { IV } & \text { V-VII } & \text { VIII } & \text { IX-X } & \text { XI } & \text { XII } \\ \text { terg. } & \frac{4}{10} & \frac{10}{16} & \frac{4}{16} & \frac{2}{16} & \frac{6}{9} & 8 & 8 & 9 \\ \text { stern. } & \frac{4}{4} & \frac{6}{4} & \frac{6}{10} & \frac{6}{10} & 7 & 4 & 8 & 12\end{array}$

Affinity. Eosentomon temannegarai sp. n. is closely related to Eosentomon paktai Imadaté, 1965, but differs from it first of all in $\mathrm{BS}$ and in ratio of $p_{1}: p_{1}^{\prime}$ and in the length of $b_{2}^{\prime}$. Chaetotaxy is the same as in E. paktai $\mathrm{Im}$.

\section{Australentulus hauseri sp. $\mathrm{n}$.}

Figs. 3 A-G

Holotype: m.j. from Teman Negara National Park, $240 \mathrm{~m}$ alt., climax lowland rainforest, 27.6.1973 P. Schauenberg leg. Genève.

Holotype mounted in Swan's medium kept in Muséum d'Histoire naturelle de

Description : Length of body $900 \mu$, foretarsus without claw $109 \mu$.

Head. - A distinct and fairly long rostrum, LR $=5.1$ (Fig. 3 F). Maxillary palpi with two distinct lateral sensillae, tapering towards apex, well developed (fig. $3 \mathrm{~F}$ ).

Rev. Suisse de Zool., T. 83, 1976 

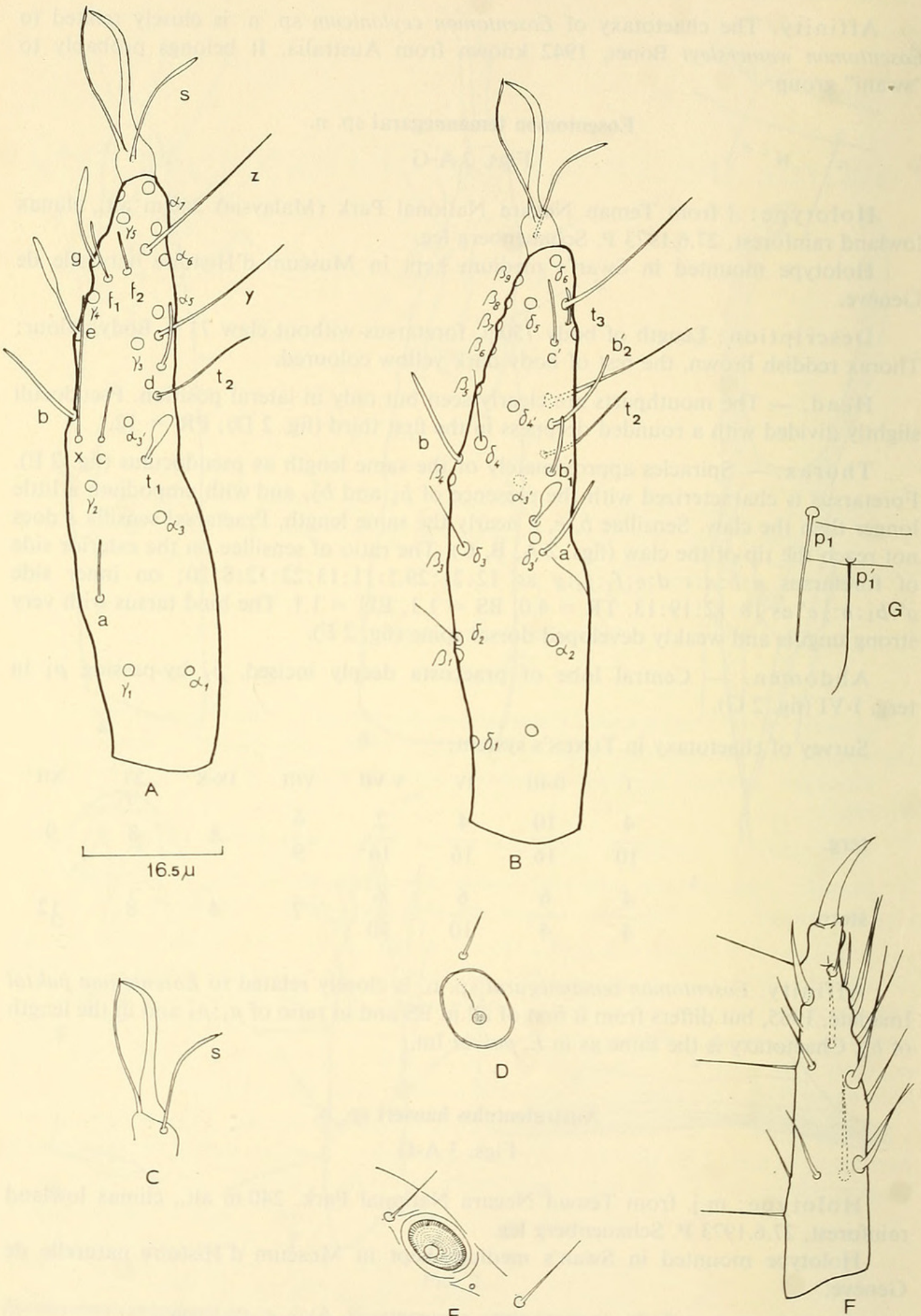

E
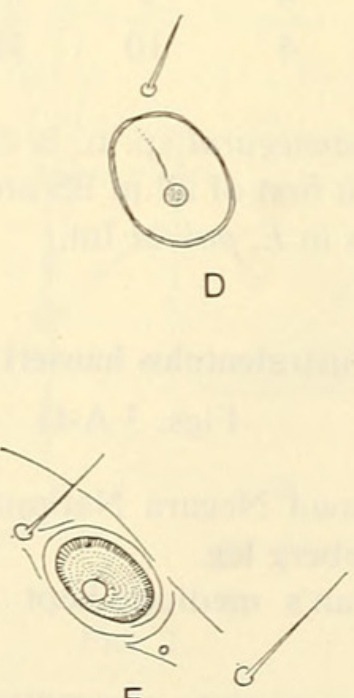

FIG. 2.

Eosentomon temannegarai sp. n. o $^{-}$: A. Foretarsus in exterior view. - B. Foretarsus in interior view. - C. The claw with empodium and sensilla $s$. - D. Pseudoculus. - E. Metathoracic spiracle. - F. The hind tarsus. 


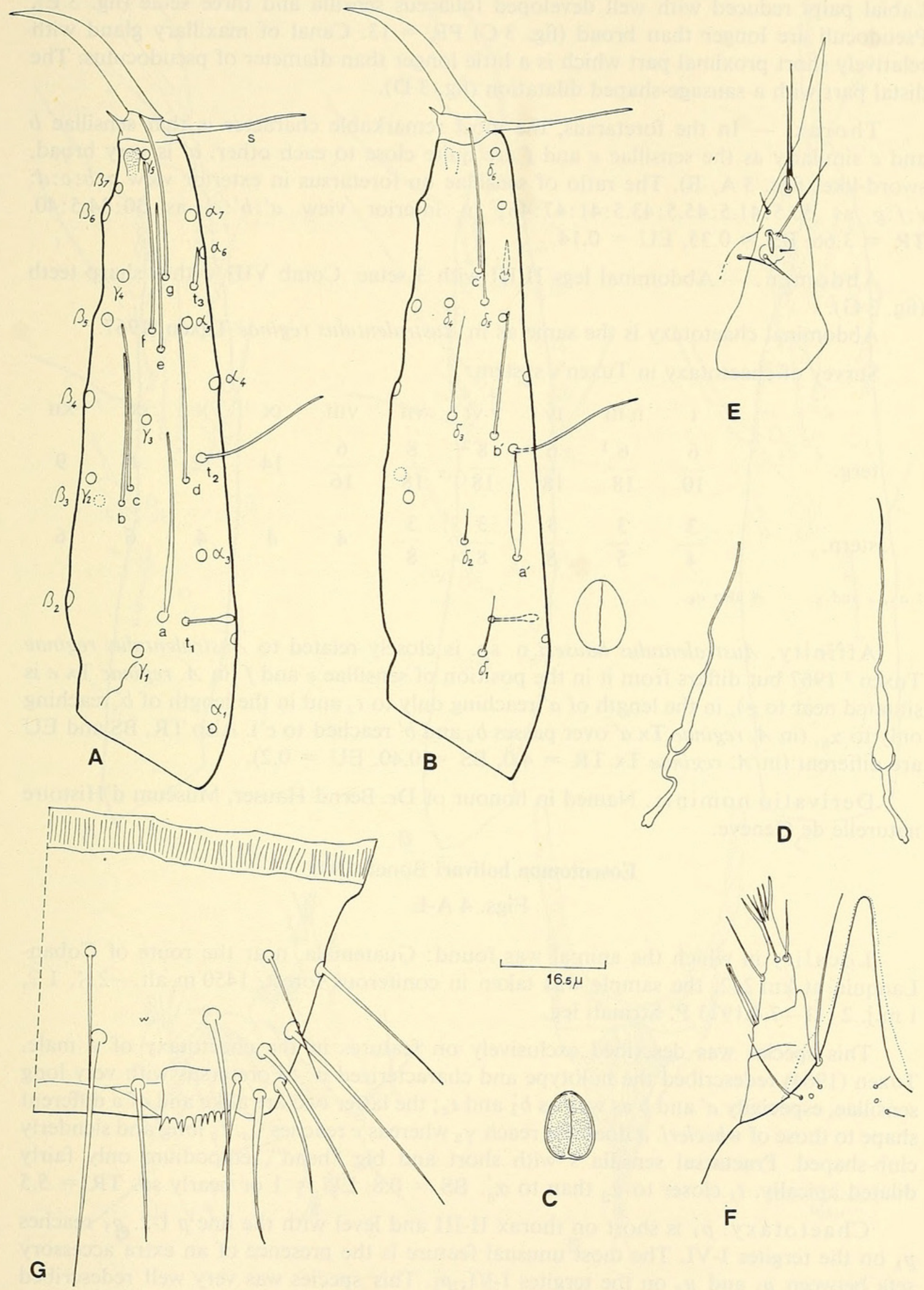

FIG. 3.

Australentulus hauseri n. sp. m.j.: A. Foretarsus in exterior view. - B. Foretarsus in interior view. - C. Pseudoculus. - D. Canal of maxillary gland. - E. Labial palp. - F. Rostrum and maxillary palp. - G. Terg. VIII with comb and chaetotaxy. 
Labial palpi reduced with well developed foliaceus sensilla and three setae (fig. $3 \mathrm{E}$ ). Pseudoculi are longer than broad (fig. $3 \mathrm{C}$ ) $\mathrm{PR}=13$. Canal of maxillary gland with relatively short proximal part which is a little longer than diameter of pseudoculus. The distal part with a sausage-shaped dilatation (fig. 3 D).

Thorax. - In the foretarsus, the most remarkable character is that sensillae $b$ and $c$ similarly as the sensillae $e$ and $f$ are quite close to each other. $a^{\prime}$ is very broad, sword-like (figs. $3 \mathrm{~A}, \mathrm{~B}$ ). The ratio of sensillae on foretarsus in exterior view $a: b: c: d$ : $e: f: g$ as $50.5: 41.5: 45.5: 43.5: 41: 47: 46$; in interior view $a^{\prime}: b^{\prime}: c^{\prime}$ as $30: 34.5: 40$. $\mathrm{TR}=3.66, \mathrm{BS}=0.35, \mathrm{EU}=0.14$.

Abdomen. - Abdominal legs II-III with 3 setae. Comb VIII with 9 sharp teeth (fig. $3 \mathrm{G}$ ).

Abdominal chaetotaxy is the same as in Australentulus reginae Tuxen, 1967.

Survey of chaetotaxy in Tuxen's system:

$\begin{array}{ccccccccccc} & \text { I } & \text { II-III } & \text { IV } & \text { V-VI } & \text { VII } & \text { VIII } & \text { IX } & \text { X } & \text { XI } & \text { XII } \\ \text { terg. } & \frac{6}{10} & \frac{6^{1}}{18} & \frac{6}{18} & \frac{8^{2}}{18} & \frac{8}{18} & \frac{6}{16} & 14 & 12 & 6 & 9 \\ \text { stern. } & \frac{3}{4} & \frac{3}{5} & \frac{3}{8} & \frac{3}{8} & \frac{3}{8} & 4 & 4 & 4 & 6 & 6 \\ 1 a_{1,2} \text { and }{ }_{5} . & \text { 2 also } a_{4} \text {. } & & & & & & & & & \end{array}$

Affinity. Australentulus hauseri n. sp. is closely related to Australentulus reginae Tuxen ${ }^{1} 1967$ but differs from it in the position of sensillae $e$ and $f$ (in $A$. reginae Tx $e$ is situated near to $g$ ), in the length of $a^{\prime}$ reaching only to $t_{2}$ and in the length of $b^{\prime}$ reaching only to $\alpha_{5}$. (in $A$. reginae Tx $a^{\prime}$ over passes $b_{2}$ and $b^{\prime}$ reached to $c^{\prime}$ ). Also TR, BS and EU are different (in $A$. reginae $\mathrm{Tx} \mathrm{TR}=4.0, \mathrm{BS}=0.40, \mathrm{EU}=0.2$ ).

Derivatio nominis. Named in honour of Dr. Bernd Hauser, Muséum d'Histoire naturelle de Genève.

Eosentomon bolivari Bonet, 1949

Figs. 4 A-E

Locality in which the animal was found: Guatemala, near the route of Coban-

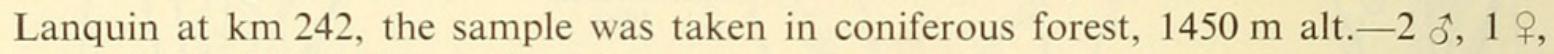
1 m.j. 21 II-7.4.1973 P. Strinati leg.

This species was described exclusively on features in the chaetotaxy of a male. Tuxen (1964) redescribed the holotype and characterized it: "Foretarsus with very long sensillae, especially $a^{\prime}$ and $b$ as well as $b_{2}^{\prime}$ and $t_{2}$; the latter two are alike and of a different shape to those of wheeleri. $a$ does not reach $\gamma_{2}$ whereas $c$ reaches $\gamma_{3}$. $f_{2}$ long and slenderly club-shaped. Praetarsal sensilla $s$ with short and big "head", empodium only fairly dilated apically. $t_{1}$ closer to $\alpha_{3}$ than to $\alpha_{3}^{\prime}$. BS $=0.8, \mathrm{EU}=1$ or nearly so. $\mathrm{TR}=5.5$

Chaetotaxy. $p_{1}^{\prime}$ is short on thorax II-III and level with the line $p$ 1-2. $p_{1}^{\prime}$ reaches $p_{1}$ on the tergites I-VI. The most unusual feature is the presence of an extra accessory seta between $p_{1}$ and $p_{2}$ on the tergites I-VI, $p_{1}^{\prime \prime}$. This species was very well redescribed

1 My thanks are due to Prof. Dr. S. L. Tuxen, Universitetets Zoologiske Museum, Copenhagen, for comparison of $A$. hauseri with Australian material of reginae Tx ( $\left.\sigma^{\wedge}\right)$. 

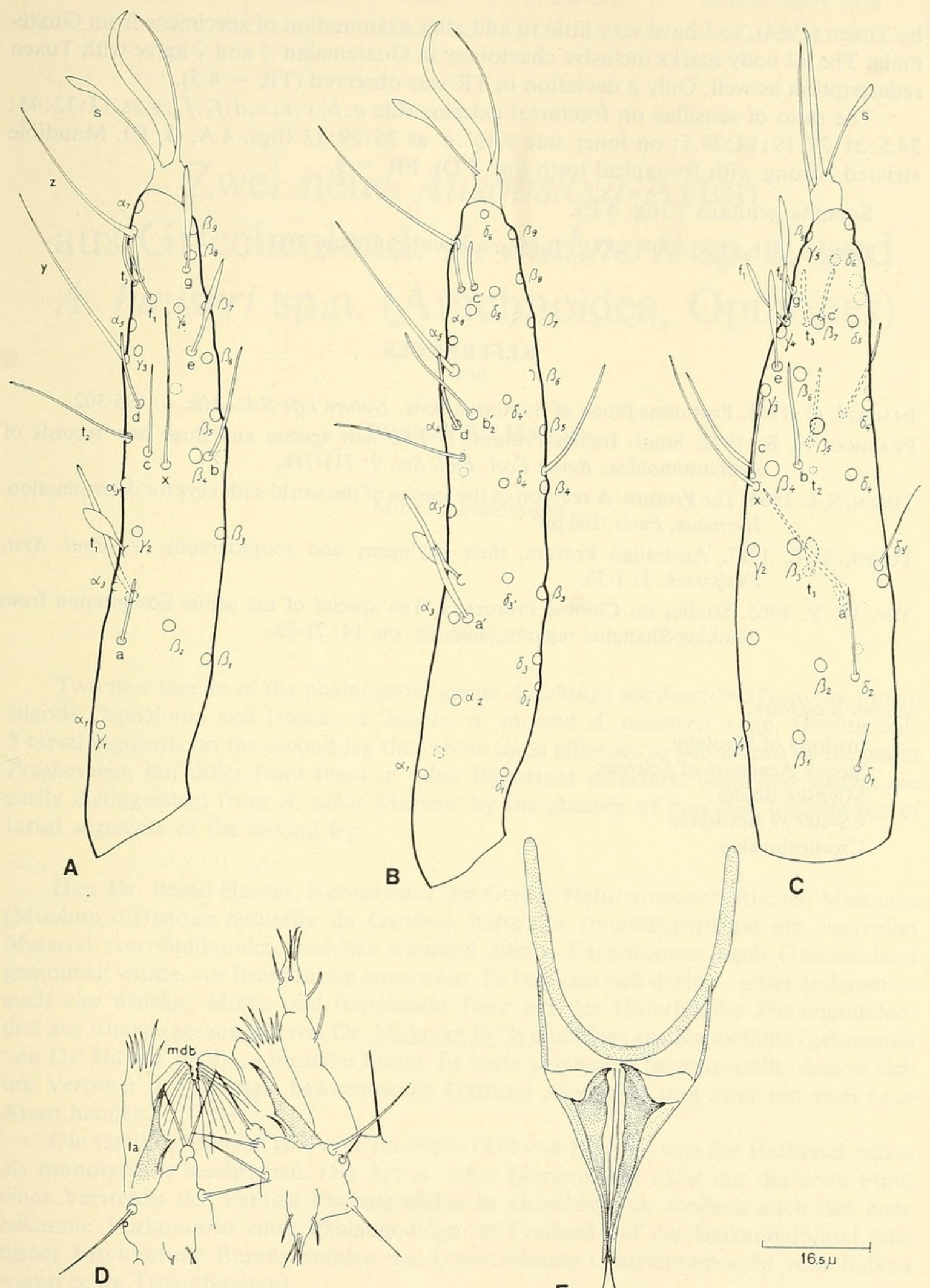

B
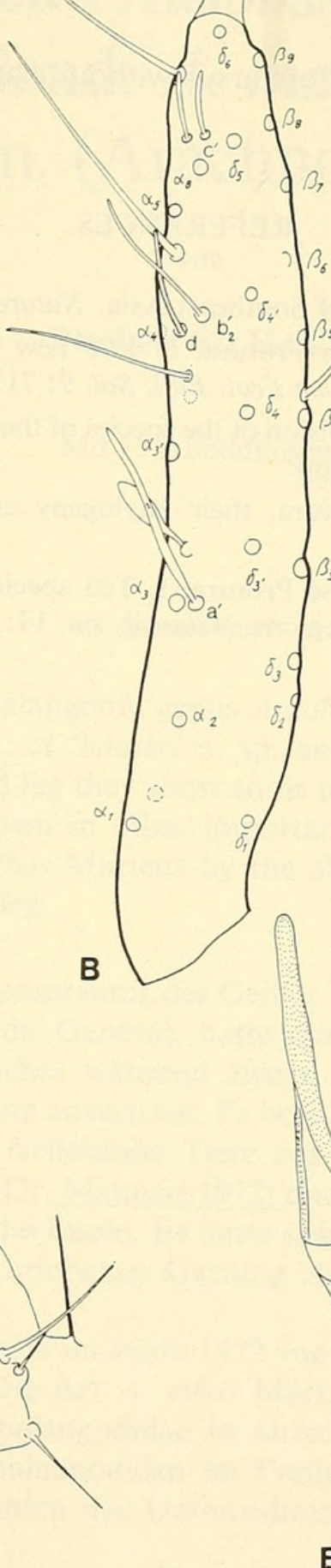

FIG. 4.

Eosentomon bolivari Bonet, 1949: A. Foretarsus in exterior view $(\widehat{\jmath})$. - B. Foretarsus in interior view $(\hat{o})$. - C. Foretarsus in ventral view $(+)$. — D. Mouthparts: mdb - mandible. — E. Squama genitalis $ᄋ$. 
by Tuxen (1964), so I have very little to add after examination of specimens from Guatemala. The all body marks inclusive chaetotaxy in Guatemalan $\sigma^{t}$ and $q$ agree with Tuxen redescription as well. Only a deviation in TR was observed $(\mathrm{TR}=4.5)$.

The ratio of sensillae on foretarsal exterior side $a: b: x: c: c: d: f_{1}: f_{2}: g$ as $17: 32: 43$ : $24.5: 21: 27: 19: 14: 28.5$; on inner side $a^{\prime}: b^{\prime}: c^{\prime}$ as $38: 29: 13$ (figs. $4 \mathrm{~A}, \mathrm{~B}, \mathrm{C}$ ). Mandible striated, strong with few apical teeth (fig. 4 D). $P R=9$.

Squama genitalis + (fig. $4 \mathrm{E}$ ).

Length of body $1400-1500 \mu$, foretarsus without claw $109 \mu$.

\section{REFERENCES}

ImadatÉ, G. 1965. Proturans-fauna of Southeast Asia. Nature Life S.E. Asia. 6: 195-302.

Prabhoo, N. R. 1972. South Indian Protura. I. Two new species and three new records of Acerentomoidea. Revue Écol. Biol. Sol. 9: 711-718.

Tuxen, S. L. 1964. The Protura. A revision of the species of the world with keys for determination. Hermann, Paris. 360 pp.

Tuxen, S. L. 1967. Australian Protura, their phylogeny and zoogeography. Z. Zool. Syst. Evolforsch. 5: 1-53.

YIN, W. Y. 1965. Studies on Chinese Protura. I. Ten species of the genus Eosentomon from Nanking-Shanghai regions. Acta ent. sin. 14: 71-92.

Author's address :

Institute of Virology

Slovak Academy of Sciences

Mlynska dolina

CS-809 39 Bratislava

Czechoslovakia 


\section{$2 \mathrm{BHL}$ Biodiversity Heritage Library}

1976. "Towards the knowledge of tropical Protura." Revue suisse de zoologie 83, 255-262. https://doi.org/10.5962/bhl.part.91438.

View This Item Online: https://www.biodiversitylibrary.org/item/129622

DOI: https://doi.org/10.5962/bhl.part.91438

Permalink: https://www.biodiversitylibrary.org/partpdf/91438

\section{Holding Institution}

Smithsonian Libraries

\section{Sponsored by}

Biodiversity Heritage Library

\section{Copyright \& Reuse}

Copyright Status: In Copyright. Digitized with the permission of the rights holder.

Rights Holder: Muséum d'histoire naturelle - Ville de Genève License: http://creativecommons.org/licenses/by-nc-sa/3.0/

Rights: https://www.biodiversitylibrary.org/permissions/

This document was created from content at the Biodiversity Heritage Library, the world's largest open access digital library for biodiversity literature and archives. Visit BHL at https://www.biodiversitylibrary.org. 